\title{
Parenting Styles and Practices in Children's Obesogenic Behaviors: Scientific Gaps and Future Research Directions
}

\author{
Heather Patrick, PhD, Erin Hennessy, PhD, MPH, ${ }^{2}$ Kate McSpadden, MA, ${ }^{3}$ and April Oh, $\mathrm{PhD}, \mathrm{MPH}^{4}$
}

\begin{abstract}
Given the emerging global childhood obesity epidemic and the specter of a generation of children who will have a shorter life expectancy than that of their parents, recent research has focused on factors that influence children's weight status and obesogenic behaviors (i.e., eating, physical activity, and screen media use). Parents act as primary socializing agents for children, and thus growing evidence supports the role of parenting styles and practices in children's obesity-related behaviors and weight. Studying these processes in children and adolescents is important for several reasons. First, diet and physical activity behaviors and weight status track from childhood and adolescence into adulthood. Furthermore, diet and physical activity behaviors and weight status confer significant risk for cancer, diabetes, cardiovascular disease, and other chronic diseases. The purpose of this article is to describe the scientific gaps that need to be addressed to develop a more informed literature on parenting styles and practices in the domains of weight status and obesogenic behaviors, as identified by an expert panel assembled by the National Cancer Institute.
\end{abstract}

\section{Introduction}

I n the context of the growing childhood obesity epidemic, recent research has aimed to address the major precursors to childhood obesity and obesogenic behaviors (i.e., eating, physical activity, and screen media use). An increasing volume of research has focused on the role of parents as primary socializing agents for children's eating and activity patterns for two important reasons. First, rates of obesity among adults are at an all time high, with nearly $36 \%$ of US adults obese. ${ }^{1}$ Therefore, parents are often faced with attempting to engender behaviors in their children that they are not executing well themselves or are struggling to maintain. Second, parents act as socializing agents during critical periods of development. Childhood and adolescence represent important life stages for primary prevention because the behavioral patterns established during these years tend to track into adulthood. ${ }^{2}$ Furthermore, children and adolescents who are obese are more likely to be obese as adults, putting them at increased risk for a variety of negative health consequences, including hypertension, dyslipidemia, cardiovascular disease, type 2 diabetes, and several cancers. ${ }^{3,4}$ Thus, parents are prime agents for promoting healthful behaviors among their children with the potential to impact a healthier life course.

Given the importance of weight status, eating patterns, and physical activity in cancer prevention and control, and the role that parents play in establishing these health and behavior patterns in their children, the National Cancer Institute (NCI) convened a meeting of invited experts in the Fall of 2011. The purpose of this meeting was to bring together a multidisciplinary group of experts in parenting research to discuss the role of parents in cancer-preventive behaviors. Meeting discussions focused on the current state of the evidence and major scientific gaps. The International Society for Behavioral Nutrition and Physical Activity (ISBNPA) 2012 preconference workshop on parenting measurement provided an opportunity to inform the broader research community on the discussions that emerged and conclusions that were derived from the NCI-sponsored meeting.

This article begins with a brief overview of the extant literature on parenting styles and practices generally and

\footnotetext{
'Division of Cancer Control and Population Sciences, National Cancer Institute, Bethesda, MD.

${ }^{2}$ Cancer Prevention Fellowship Program, National Cancer Institute, Bethesda, MD.

${ }^{3}$ National Catholic School of Social Service, The Catholic University of America, Washington, DC.

${ }^{4} \mathrm{SAIC}-$ Frederick, Inc., NCl-Frederick, Frederick, MD.
} 
with respect to obesogenic behaviors in particular. The article then describes four major scientific gaps in this literature. These gaps include: (1) The need for greater integration of the concept of parenting styles in the literature on parenting practices within the context of children's obesogenic behaviors; (2) understanding the mechanisms through which parenting practices influence children's obesogenic behaviors, including both mediators and moderators of these associations; (3) characterizing the role of broader social and environmental factors influencing parenting styles and practices; and (4) studying the relationship processes involved in parenting and obesogenic behaviors, including the bidirectional nature of the parent-child relationship and the importance of coparenting. The article concludes with a discussion of how improvements in measurement and the development of a comprehensive conceptual framework could address these limitations and facilitate future research.

\section{Parenting Styles and Practices}

Stemming from the broader literature in developmental psychology, a burgeoning evidence base has emerged regarding the role of parenting styles and parenting practices in children's obesogenic behaviors. Parenting practices refer to specific behaviors that parents engage in when attempting to socialize their children, whereas parenting styles reflect the broader emotional and relational climate created by the ways in which parents go about these socialization attempts. Thus, parenting practices generally address what parents do, while parenting styles address how they do it. Consider the parenting practice of limiting screen time (e.g., time spent watching TV, playing video or computer games, using a mobile phone or other mobile device). Parents may limit screen time by discussing why screen time limits are important and negotiating how much screen time is allowed (authoritative style). Alternatively, parents may function as the long arm of the law, where rules are set with little child engagement (authoritarian style). Or, parents may provide insufficient structure and allow children to monitor themselves with little parental input (permissive style).

Research on the effects of parents on child development began in the 1920s with much of the early work focusing on infant and toddler care practices. ${ }^{5}$ A lack of statistically significant findings regarding specific parenting practices led to research on more global characteristics of parenting. This line of research identified global dimensions along which parents differed in their behavior toward their children. Baumrind identified two such dimensionsresponsiveness/nurturance and demandingness/control. ${ }^{6}$ Responsiveness/nurturance involves fostering the child's individuality and independence by attending to, supporting, and agreeing to the child's requests. Demandingness/ control has been characterized as socializing the child through direct attempts to regulate behavior, supervising the child's activities, and setting expectations for maturity. These two dimensions gave rise to three parenting style typologies - authoritative, authoritarian, and permissive. Maccoby and Martin ${ }^{7}$ expanded this conceptualization to include a fourth typology-uninvolved or neglectful. Table 1 presents the parenting style typologies along the dimensions of responsiveness/nurturance and demandingness/control.

General parenting research has focused mostly on child outcomes, such as school achievement, social adjustment among peers, and alcohol and drug-related problems in adolescence. ${ }^{8}$ Evidence generally supports the association between authoritative parenting and positive child and adolescent outcomes across multiple domains, including various health and health behavior contexts, psychological adjustment, and academic achievement. ${ }^{9,10}$ However, research on parenting styles has mostly been conducted among Euro-American, middle-class populations. Research involving samples with greater racial/ethnic and socioeconomic diversity have yielded somewhat different findings. ${ }^{11-15}$ Studies examining the cultural context of parenting in the United States have demonstrated that different racial/ethnic groups hold different goals for their children and therefore use different child-rearing practices. For example, high levels of parental control often predict negative health and psychosocial outcomes for EuroAmerican, middle-class children and adolescents but have been related to positive outcomes in Asian-American and African-American children and adolescents. ${ }^{1-15}$

More recently, researchers have begun to explore parenting styles and practices in the domain of childhood obesity and obesogenic behaviors. Much of the research in this domain has focused on the associations between specific parenting practices and child outcomes, like fruit and vegetable intake or physical activity level. The role of parenting practices in children's eating behaviors (i.e., feeding styles) is the obesity-relevant domain that has received the most attention. ${ }^{16}$ Practices that fall along the demandingness/control end of the spectrum, such as restricting and monitoring, have been associated with child

Table I. Baumrind's (197I) and Maccoby and Martin's (1983) Typology of Parenting Styles

\begin{tabular}{l|l|l|l|}
\multirow{2}{*}{ Responsiveness/nurturance } & \multicolumn{2}{c}{ Demandingness/control } \\
\cline { 2 - 4 } & High & Authoritative & Lerm \\
\cline { 2 - 4 } & Low & Authoritarian & Uninvolved/neglectful \\
\hline
\end{tabular}


behaviors such as eating in the absence of hunger and eating more sweet and savory snacks when the child is away from direct parental supervision. ${ }^{17}$ Responsiveness/ nurturance practices, such as providing a rationale for food rules, have been associated with greater intake of fruit and vegetables. Emerging research suggests that permissive and uninvolved practices, characterized by a lack of structure, are associated with the poorest dietary behaviors and weight outcomes, including lower fruit and vegetable intake and greater likelihood of the child being overweight or obese. ${ }^{17}$ Regarding the role of parenting in children's physical activity behaviors, and in contrast to research in other domains (e.g., children's dietary behaviors), evidence suggests that more permissive approaches are associated with greater child engagement in moderate-tovigorous physical activity. ${ }^{18,19}$ Finally, recent research has addressed parenting and screen media use. This line of research has indicated that providing structure and guidance, such as setting limits on how much time a child can spend using screen media or the placement of screen media devices in the home (e.g., in common areas such as the living room rather than in a child's bedroom), are associated with lower screen media use. ${ }^{20}$

\section{Parenting and Children's Obesogenic Behaviors: Scientific Gaps}

\section{The Need for Greater Integration of Parenting Styles}

The literature on the role of parents in children's obesogenic behaviors has provided important contributions to understanding children's eating, activity, and screen media use behaviors. However, much of the existing literature has focused primarily on parenting practices - that is, the specific behaviors parents engage in to address children's obesogenic behaviors. Less research has addressed broader parenting styles - the emotional and relational environment that parents create in their interactions with their children. It is possible that parenting styles operate at a more global level than parenting practices. That is, parenting styles may reflect the general ways in which parents interact with their children around a variety of behaviors, including academics, friendships, and obesogenic and other health behaviors. These more global ways of interacting may serve as the basis from which specific parenting practices emerge. Better integration of parenting styles' influence on parenting practices in the eating, activity, and screen media domains may lend important insights to the existing evidence base.

Although much research has focused on parenting practices in predominantly middle-class, Euro-American samples, research addressing these same associations in more diverse samples suggests that authoritarian and restrictive practices in particular may not always result in poorer eating practices. Darling and colleagues ${ }^{21}$ suggested that parenting styles may operate as a moderator of the association between specific parenting practices and children's health and behavioral outcomes. However, this has not been well studied in the context of the role of parenting in children's obesogenic behaviors and weight status. The potential moderating role of parenting styles may be particularly important in the case of specific practices that may be experienced as more or less controlling, depending on the broader emotional and relational context in which they occur. For example, limit setting around behaviors such as screen media use and junk food intake may be very controlling if the general nature of interactions between parents and children is such that parents dictate rules and children are expected to follow them. However, limit setting may be experienced as very nurturing if the emotional and relational context of the parent-child relationship includes age-appropriate dialogue about the reasons for limits, consideration for revisiting limits, etc. Thus, how a parent interacts with their child may buffer the otherwise negative consequences of restrictive practices.

There are other possible ways in which parenting styles may further inform the literature on parenting practices for obesogenic behaviors. For example, parenting styles functioning at a global level may serve as part of a broader, hierarchical model of parenting whereby the general ways in which parents interact with their children (i.e., parenting styles) spill over to the more specific parenting practices they engage within a given behavioral domain. That is, it may be that parents who generally exhibit an authoritarian style of parenting that is high in demandingness/control and low in nurturance/responsiveness are more likely to engage specific parenting practices, such as restricting access to certain foods either by keeping them out of reach or by not bringing them into the home at all. This conceptualization of the broad ways in which parenting styles may influence specific parenting practices is consistent with the idea of parenting styles as "trait-like." It is also possible that, although parents exhibit a general approach to parenting, there is variability in parenting styles across behavioral domains (e.g., more authoritarian with regard to children's eating, more permissive with regard to children's physical activity, and more authoritative with regard to children's screen media use) and it is the parenting style in a particular domain that predicts parenting practices in that domain. As noted above, parenting styles - functioning at global or domain-specific levels - may be a key moderator of the association between parenting practices and children's obesogenic behaviors.

However, to date, most of the work on parenting in children's obesogenic behaviors has focused largely on parenting practices and has derived styles from responses to measures designed to assess practices. Research that incorporates measures of broader parenting styles - both self-report and observational-is an important next step in this line of research. Furthermore, to the extent that parenting styles reflect characteristics operating at a trait (i.e., personality) level within the parent, understanding how, whether, and under what circumstances parenting styles or practices are an appropriate target of intervention is also 
worthy of study. Interventions to date have attempted to change either specific parenting practices aimed at specific child behaviors (e.g., encouragement to eat more vegetables) or the broader family context (e.g., family functioning). ${ }^{22}$ Better integration across the literature on parenting styles and practices may serve to bridge these intervention approaches to yield improved intervention efficacy.

\section{Identifying Mechanisms by which Parenting Influences Children's Obesogenic Behaviors}

Another important gap in the existing literature on parenting and children's obesogenic behaviors is the issue of mechanism. Very little research has addressed important variables that may be in the pathway (i.e., mediators, moderators) between parenting practices and children's obesogenic behaviors. For example, research on eating in the absence of hunger has shown that children whose parents restrict their access to sweet and savory snack items eat more of the items in a free-choice setting - even after indicating they are full. ${ }^{23}$ However, it is not clear why. Some have suggested that when parents are restrictive or engage in other authoritarian practices, children have less ownership over their behavior and therefore do not develop a strong capacity to regulate these behaviors on their own. ${ }^{24}$ It is also possible that this reflects a sort of "nutritional rebellion" whereby, when given the chance, children will overindulge in forbidden foods as a sort of reactive response. Despite this speculation about important potential mediators, very little research has directly assessed variables such as children's motivation, self-regulation, self-efficacy, or reactivity in the context of parenting practices and obesogenic behaviors. Thus, it is not yet known whether parenting practices are associated with children's obesogenic behaviors, primarily because parenting practices influence other variables, like self-regulation, efficacy, or reactivity.

Another important area of study for understanding mechanisms in parenting styles and practices involves the interplay between parents and the broader social and environmental context including factors such as parenting norms, food access, and the built physical environment. For example, research investigating the extent to which broad parenting styles or specific parenting practices buffer the effects of neighborhood environments that are not conducive to healthy eating or physical activity could address how policy- and individual-level approaches might work together to address the obesity epidemic. Equally important is understanding how and under what circumstances the characteristics of neighborhood and social environments mitigate the influence of parenting styles and practices on children's obesogenic behaviors.

\section{Social and Environmental Precursors to Parenting Styles and Practices}

As the childhood obesity epidemic has emerged and researchers have sought to understand the various factors that influence children and their obesogenic behaviors, attention has been given to perspectives that take into account broader social/contextual and physical/environmental factors. The social-ecological model and other similar perspectives consider the multilevel factors that contribute to childhood obesity and obesogenic behaviors. Acknowledging not only the individual-level influences (i.e., obesogenic behaviors) that contribute to obesity, such perspectives address the complex systems involved at the interpersonal (e.g., parents), community (e.g., home, school), neighborhood (e.g., food systems, parks and recreation facilities), and social (e.g., norms, policy) levels that provide the context for obesogenic behaviors. ${ }^{25,26}$ However, despite the proliferation of research using the social-ecological or other multilevel models to understand childhood obesity, little research has applied these models to understanding how these same complex systems may influence parenting styles and practices. Thus, very little is known about the precursors to parenting styles and practices oriented toward children's obesogenic behaviors.

Consider the case of social influences such as parenting norms. There is some evidence to suggest that recent decades have seen a rise in more permissive parenting. ${ }^{27}$ Permissive parenting involves allowing children to make many decisions for themselves, setting few rules or boundaries, and aligning with children more as "friend" than as a parental "authority" figure. There are several ways in which these social and cultural norms may influence parenting styles and practices. First, parents may observe how other parents interact with their children - whether this occurs in the context of other family relationships, casual observations of other parents' behaviors, or elements of parenting portrayed in the media which may influence perceptions of socially acceptable parenting practices. Furthermore, norms around parenting may influence what children expect from their parents. For example, if a child has friends whose parents do not set rules about screen media use or do not encourage their child to eat vegetables, this may set the child's expectations for how his or her own parent should be involved in the child's screen media and eating behaviors. Thus, social and cultural norms have the potential to shape the legitimacy of parental authorityfrom both child and parent perspectives. Social and cultural norms around parenting may therefore influence the general ways in which parents and children interact and the specific practices or strategies parents use with their children around obesogenic behaviors.

Characteristics of neighborhood environments may also be important in shaping parenting styles and practices. The environment predisposes, enables, and reinforces both individual and collective behaviors. ${ }^{28}$ Current food and physical activity environments have created defaults that challenge parents' efforts to promote or maintain healthful behaviors. $^{29}$ As a function of the characteristics of the environments in and around schools and in the areas between home and school, children and adolescents have increasing access to low-nutrient dense foods because they are readily available and relatively inexpensive. Checkout 
lines at grocery stores are often stocked with candy and other snack items, and low-nutrient dense foods are present throughout grocery aisles. ${ }^{30}$ The proliferation of technology for entertainment (e.g., streaming videos, use of social media, video games) and limited safe places for activity in many neighborhoods have both worked together to create a generation of children and adolescents who spend a lot of their free (i.e., nonschool) time sitting and rarely engaged in active play. ${ }^{31}$ Thus, the environment in many ways works against parents' well-intentioned efforts to support their children's healthy eating and activity behaviors, which may create conflict between parents and children. When parents feel that they have to battle their children on multiple fronts (e.g., getting homework done, going out to play, limiting junk food intake, etc.) and they have to do so in the context of neighborhood environments that actively work against their efforts, parents may be forced to "choose their battles." As a result, parents may engage in different parenting practices than they otherwise might if the neighborhood environment more closely aligned with parents' efforts to combat obesogenic behaviors.

Parents may also experience their own environments to be particularly restrictive and controlling (e.g., financial pressures, work stress), which may spill over into how they interact with their children around obesogenic and other behaviors. Characteristics of parents that may influence parenting styles and practices in the context of obesogenic behaviors include parent education level, stress, time or financial resource limitations, and depression. ${ }^{32,33}$ In addition, there are a variety of interpersonal factors and experiences that may influence parenting styles and practices. These include parents' own experiences as children (i.e., how their parents parented), characteristics of the child that influence the parent-child relationship, and the overall family climate, including communication styles and patterns, family roles and norms, and other children and adults within the household. For example, parents may engage more pressuring practices if their child is a picky eater. If a child is averse to physical activity - either because the child has experienced negative social consequences for not being particularly athletic or because the child has a health condition that makes exercise unpleasant or even dangerous (e.g., asthma) - parents may engage more permissive and indulgent practices. Additionally, the presence of other children in the household has the potential to influence parenting styles and practices. This may be particularly the case when one or more children in the household is overweight or obese while others are normal or underweight. Several of these characteristics have been studied in the broader literature on parenting, but little research to date has addressed precursors to parenting styles and practices directed toward children's obesogenic behaviors. ${ }^{34}$

\section{Studying Relationships: Parents and Children and Co-Parenting}

One of the most substantial gaps in the literature on parenting and children's diet, physical activity, and screen media use behaviors is that the relationships involved between parents and children and between multiple adults responsible for the child's health and well-being (i.e., coparenting) have not been addressed. Regarding the parentchild relationship, to date the literature on parenting and obesogenic behaviors has been largely unidirectional, using models that characterize the parent as the agent acting upon the child. ${ }^{17}$ However, there is likely bidirectional feedback between parenting practices and child behaviors such that parenting practices may increase, decrease, or change approach in response to child behaviors or other characteristics, such as child responsiveness to parenting efforts. Consider the case of limit setting around playing video games. A parent may set limits with the child about how many hours and under what circumstances (e.g., after homework is done) the child may play video games. If the child follows those rules, playing video games only after homework is completed and only during the agreed-upon times, the parent is likely to continue with those rules in place and perhaps engage the child in future dialogue about rule setting around other behaviors. On the other hand, if the child does not follow the rules, at least two parent responses are possible: (1) The parent may change course by establishing stricter limits or taking away video game privileges; or (2) the parent may continue with the same course even though the practice of limit setting is ineffective. The general parenting literature has addressed the bidirectional nature of parenting practices and child responsiveness, ${ }^{35,36}$ although this has been less welldeveloped with regard to parenting and children's obesogenic behaviors.

Furthermore, in part because much of the literature has focused on younger children who may be unable to respond to traditional self-report measures of parenting practices, little research has examined how children's perceptions of parent's attempts to socialize their behavior around eating, activity, and screen media use influence children's obesogenic behaviors and weight status. Instead, the literature has relied almost exclusively on parents' reports of their own behaviors (i.e., practices). However, it is equally important to acknowledge and understand how children interpret and perceive those practices. Although the literature has identified certain practices (e.g., monitoring, restricting) as more controlling or demanding, children may experience those parenting behaviors as nurturing and providing structure. More research is needed to further understand how children perceive parenting styles and practices and how those perceptions may influence children's obesogenic behaviors. Few studies have included measures of both parent and child reports of parenting styles and practices. As a result, the literature has missed an opportunity to capitalize on data coming from multiple individuals within the same family, in this case parent and child. By collecting data from both parent and child on variables such as parenting styles and practices, researchers could address important questions such as (1) the extent to which parents and children perceive parenting 
styles and practices in similar or dissimilar ways and (2) how both parents' and children's perceptions of parenting styles and practices uniquely and jointly predict children's obesogenic behaviors. Qualitative methods such as focus groups and semistructured interviews with children and adolescents across the developmental course may provide important insights for how to better measure parenting styles and practices from child and adolescent perspectives.

Additionally, to date, research on parenting practices in the obesity domain has almost exclusively focused on a single parent or parenting figure (often the mother), with little consideration for how co-parenting and the relationship between the child and other parent figures may influence obesogenic behaviors and subsequent weight status. Furthermore, there is some evidence that parenting practices from mothers and fathers may differentially influence child behaviors. For example, maternal authoritative parenting styles predicted lower BMI in adolescents, whereas paternal permissive parenting practices were associated with higher BMI in preschoolers. ${ }^{37,38}$ Issues of coparenting (i.e., how multiple adults responsible for the child interact with each other around parenting responsibilities) may be particularly important in the context of the changing landscape of family structures. Due to the increase in separation and divorce in much of the Western world, many children live primarily with one parent but spend part of their time living with another. ${ }^{39}$ How those adults negotiate parenting styles and practices and their relationship to each other has important implications for children's obesogenic behaviors. Consider the example of a parent who is concerned about his child's weight status. This parent may attempt to socialize his child's eating behavior by limiting the availability of junk food in the house, encouraging the child to make healthier food choices when eating out, or setting limits on when and whether the child can have dessert or some other treat. That parent's efforts may be supported or undermined through co-parenting. If the other parent provides similar structure and limits, this may bolster efforts to support the child's healthy eating. However, if the other parent thinks the child should be allowed to eat whatever the child wants and indulges the child's sweet tooth on demand, this may undermine the first parent's efforts to promote a healthier diet for the child.

These issues can become even more complicated when parents are in conflict or when one parent has very limited time with the child. As has been shown in other literatures, when one parent has limited time with the child, that parent wants those interactions to be positive and enjoyable, so the parent may place minimal demands on the child, in part, as an effort to establish rapport and gain favor with the child. ${ }^{40,41}$ Finally, as noted above, having data on parents' and children's perceptions of parenting styles and practices could yield important insight into how parents and children interact with each other and how these interactions, and perceptions of interactions, predict children's obesogenic behaviors. In the same way, it may be important to collect data from both parents and from children to better model co-parenting and children's perceptions of similarities and differences between their parents around obesogenic behaviors. Although most research has focused on the relationship between parent and one child, certainly with more than one child in the home, parenting styles and practices and child perceptions could vary between siblings. Research that better characterizes the relationships between parents and children, multiple adults in the household (e.g., co-parents), and the role of siblings as potential sources of influence on other children as well as adults in the household is needed. Family systems theory - a perspective that has long been used in the broader developmental literature and that characterizes the family as an emotional unit - could inform this line of research. $^{42}$

\section{Next Steps: Toward Improved Measures and a Conceptual Framework}

\section{Measurement Considerations}

As noted throughout this special issue, there is a critical need to develop measures that address the range of parenting practices and how parenting practices may differ across obesogenic behavioral domains. Indeed, the approaches that parents use in trying to get their children to be more physically active may be somewhat different from their approaches in getting children to spend less time using screen media. Likewise, attempts to get children to eat fewer sweet or savory snacks may involve somewhat different parenting strategies than attempts to get children to eat more fruit and vegetables. Having better measures across each of these behaviors will provide important insight into understanding how children develop regulatory capacity in these domains and potential leverage points for interventions.

In addition to developing psychometrically sound measures of specific parenting practices, it is important to develop and incorporate broader measures of parenting styles in research on parenting for obesogenic behaviors. Including measures of parenting styles - and not merely aggregates of measures of parenting practices - could further elucidate the circumstances under which particular parenting practices may be more or less beneficial for yielding desired behavioral outcomes. Assessing parenting styles may also contribute to a more sophisticated understanding of differences that may emerge between racial/ ethnic and socioeconomically diverse samples. Measures of parenting styles will likely need to be more experiential rather than tied to specific behaviors per se. For example, items geared toward assessing a child's perceptions of his or her parent(s) might include content regarding the extent to which one's parent(s) support a child in making his or her own decisions or the extent to which the child experiences unconditional positive regard from a parent. There 
are a variety of parenting practices that may or may not function in such a way as to support a child or adolescent feeling like their parent allows them to have choice in their direction or that they are accepted unconditionally by a parent. By not tying these items to particular behaviors, measures of parenting style may be better able to assess the extent to which the child or adolescent experiences demandingness/control and nurturance/responsiveness and may better capture the emotional and relational climate that parenting styles are thought to create and represent.

Although some researchers working in adolescent populations have incorporated measures of parenting practices from the perspective of the adolescent, more research is needed to address the unique role of parent and child or adolescent perceptions of parenting practices (and styles) in predicting children's obesogenic behaviors. Thus, it is important to develop measures that are comparable across the developmental span. This will facilitate research that examines bidirectional, reciprocal associations between parents and children and between multiple children within a household. Having comparable measures available across the developmental course of childhood and adolescence is also critical to understanding whether and when parenting styles and practices change in response to the changing circumstances of children and adolescents as they evidence greater independence and deal with developmentally emerging issues such as body image, accessibility of sports, and social norms around screen media use.

\section{The Need for a Conceptual Framework}

The development of a conceptual framework in the literature on parenting and children's obesogenic behaviors may help to address the scientific gaps described above in several important ways. Theory provides a lens through which to view behaviors, interpret findings, and understand the ways in which complex variables and associations interrelate. Theoretical and conceptual models convey mechanism; they address how (i.e., mediators) and under what circumstances (i.e., moderators) variables are likely to be associated. Thus, theoretical and conceptual models may offer important insights into additional and, in some cases, more proximal targets for intervention. Below, two perspectives are provided that may have important implications for addressing existing gaps in the literature on the role of parenting in children's obesogenic behaviors - selfdetermination theory and systems science. Although there are most certainly other perspectives that are potentially applicable, these two perspectives were chosen based on their conceptual congruence with the existing literature on parenting and obesogenic behaviors and their potential to address the major scientific gaps highlighted in this article - underlying mechanisms, the bidirectionality that exists within the parent-child relationship, the complexities involved in parent-child and co-parenting relationships, and the role of broader social and contextual factors that may influence parenting styles and practices. These perspectives and their particular relevance to the literature on parenting and children's obesogenic behaviors are described, in brief, below.

Self-determination theory: Implications for parenting and child obesity. Self-determination theory (SDT) is a general theory of human motivation that addresses the extent to which behaviors are self-endorsed and volitional versus pressured or coerced. ${ }^{43,44}$ One of the unique aspects of SDT is its acknowledgement of both intrinsic (i.e., engaging in behaviors because the behavior itself is inherently enjoyable or valued) and extrinsic (i.e., engaging in behaviors for some separable outcome) motivation, and a characterization of extrinsic motivation as varying in degree of internalization or integration. Thus, not all forms of extrinsic motivation are equivalent. This is particularly important in the context of health behaviors that often fall along the continuum of extrinsic motivation (i.e., people engage in, or encourage their children to engage in, health behaviors for separable outcomes that vary in the degree to which they are more or less internalized or integrated with one's sense of self).

According to SDT, the social context may support or thwart the process by which relatively more external forms of motivation become more internalized. SDT has conceptualized the social context in terms of supporting or thwarting basic psychological needs for autonomy (i.e., the need to feel volitional, as the originator of one's actions), competence (i.e., the need to feel capable of achieving desired outcomes), and relatedness (i.e., the need to feel close to and understood by important others). ${ }^{43}$ Table 2 presents some examples of how psychological need support may be manifested behaviorally. Psychological need support has been operationalized as consisting of a number of critical elements, including offering and respecting choices, giving a meaningful explanation for recommended courses of action, and avoiding controlling language and

\begin{tabular}{l|l}
$\begin{array}{l}\text { Table 2. Examples of Need-Supportive } \\
\text { Behaviors: A Self-Determination }\end{array}$ \\
Theory Perspective \\
$\begin{array}{l}\text { Psychological } \\
\text { need }\end{array}$ & \multicolumn{1}{|c}{ Need-supportive behaviors } \\
$\begin{array}{l}\text { Autonomy } \\
\text { support }\end{array}$ & $\begin{array}{l}\text { Elicit the person's (child's) perspective, emotions. } \\
\text { Provide a menu of options from which to choose. } \\
\text { Provide rationale for advice given. } \\
\text { Minimize control/avoid judgment. }\end{array}$ \\
\hline $\begin{array}{l}\text { Competence } \\
\text { support }\end{array}$ & $\begin{array}{l}\text { Be positive about potential for success. } \\
\text { Identify barriers. } \\
\text { Skills building/problem solving. } \\
\text { Create an appropriate level of challenge. }\end{array}$ \\
\hline $\begin{array}{l}\text { Relatedness } \\
\text { support }\end{array}$ & $\begin{array}{l}\text { Develop a warm, positive relationship. } \\
\text { Provide unconditional positive regard. } \\
\text { Be empathic with the person's (child's) } \\
\text { concerns, etc. }\end{array}$ \\
\hline
\end{tabular}


guilt, as well as refraining from use of performancecontingent rewards and punishments. ${ }^{44,45}$ This is not an exhaustive list, but it does provide a flavor of what need support "looks like." It is worth noting that, from the perspective of SDT, the need for autonomy is not synonymous with independence. One may volitionally choose to rely on others and seek their input, and the social context can provide input in ways that support or thwart an individual's capacity to act volitionally and personally endorse one's behaviors.

There is a great deal of conceptual overlap between SDT's characterization of the social environment as needsupportive versus need-thwarting and the broader literature on parenting styles. For example, as described above, supporting psychological needs involves providing structure in the form of a menu of options from which to choose and providing a rationale for recommended behavior. These practices are largely consistent with authoritative parenting. In contrast, social contexts that have been characterized as controlling or need-thwarting are those in which an authority figure is much more directive and demanding. This may take the form of conditional regard or unilateral decision-making on the part of a parent regarding rules and limits, with little or no provision of rationale and little or no input from the child. ${ }^{46}$ Some confusion has arisen when SDT autonomy is made synonymous with independence. Thus, some have described autonomy-support as lacking structure, boundaries, or guidance. This is, in fact, closer to permissive or neglectful/uninvolved parenting. However, it is not consistent with the tenets of psychological need support broadly or autonomy-support in particular. A fairly substantial body of research in the SDT literature has examined the role of parents' support of children's psychological needs in a variety of domains, including academic achievement, ${ }^{47,48}$ involvement in sports, ${ }^{49}$ emotion regulation, ${ }^{50}$ identity development ${ }^{51}$ and mental health. ${ }^{52}$ It, thus, may be useful to extend this line of research from SDT and further test similarities between SDT's concept of psychological need support and parenting styles and practices.

Beyond the conceptual similarities between SDT and parenting styles, SDT may also offer some insight into potential mechanisms through which parenting styles or practices influence children's obesogenic behaviors. From the perspective of SDT, more internalized forms of selfregulation emerge from social contexts that support psychological needs, and self-regulation has been hypothesized to be one mechanism through which parenting practices affect children's behaviors. Importantly, in the broader literature on SDT-based interventions, support for basic psychological needs from healthcare providers has been shown to facilitate more internalized self-regulation, and more internalized forms of self-regulation have been associated with sustained behavior change and behavioral maintenance in the absence of ongoing intervention. ${ }^{53}$ This finding has particularly important implications for the role of parents in supporting children's long-term adoption of weight-relevant health behaviors and may provide further rationale for developing and implementing interventions targeting parenting practices. Future research could test (1) the extent to which parenting styles and practices support versus thwart basic psychological needs, and (2) the extent to which parenting styles and practices operate on putative mediators identified by SDT and other health behavior theories, including children's self-regulation of and perceived competence for obesogenic behaviors.

SDT has also proposed a motivational hierarchy by which motivation operating at trait levels spills over to influence motivation operating at domain-specific levels. ${ }^{54}$ Parenting styles and practices may work similarly, as shown in Figure 1. Research is needed to further clarify the extent to which a similar hierarchy exists between parenting styles, parenting practices in particular domains, and children's subsequent behavior in those domains. Importantly, it is worth noting that most SDT-based interventions, including in the areas of diet, physical activity, and weight management, have sought to operate at the domain-specific level of motivation. That is, rather than targeting trait-level motivational constructs, SDT-based interventions attempt to facilitate the process of internalization toward more autonomous and integrated forms of self-regulation in a specific behavioral domain. The means by which such change in motivation is achieved by practitioners (e.g., physicians, physical activity counselors, etc.) is by supporting the client's or patient's basic psychological needs. ${ }^{55,56}$ If research indicates that parenting styles and practices function within a similar hierarchy, additional research will be needed to clarify whether interventions should target specific parenting practices or if there are other means by which children's obesogenic behaviors can best be intervened upon through parents, including parenting styles and practices.

Finally, SDT may offer a model for developing new measures to assess parenting styles to move beyond the current approach, which involves deriving styles from measures of parenting practices. First, measures of psychological need satisfaction and the nature of parent-child relationships in SDT have, by and large, focused on assessing the general ways in which parents interact with children rather than the specific behavioral practices parents enact. For example, items assess the extent to which parents are available for their children to talk to them, parents' emotional responses to children, and the extent to which parents engage children in decision-making and discussions about household and other rules. Second, these measures have included assessments of children's perceptions of their parents, rather than relying on parent reports of their own behavior. Children respond to items separately for their mother and for their father. This approach to measurement acknowledges the importance of children's perceptions of how their parents interact with them-i.e., how children experience their parents' interaction styles - and also addresses how the multiple adults involved in children's care (i.e., mothers and fathers) may 


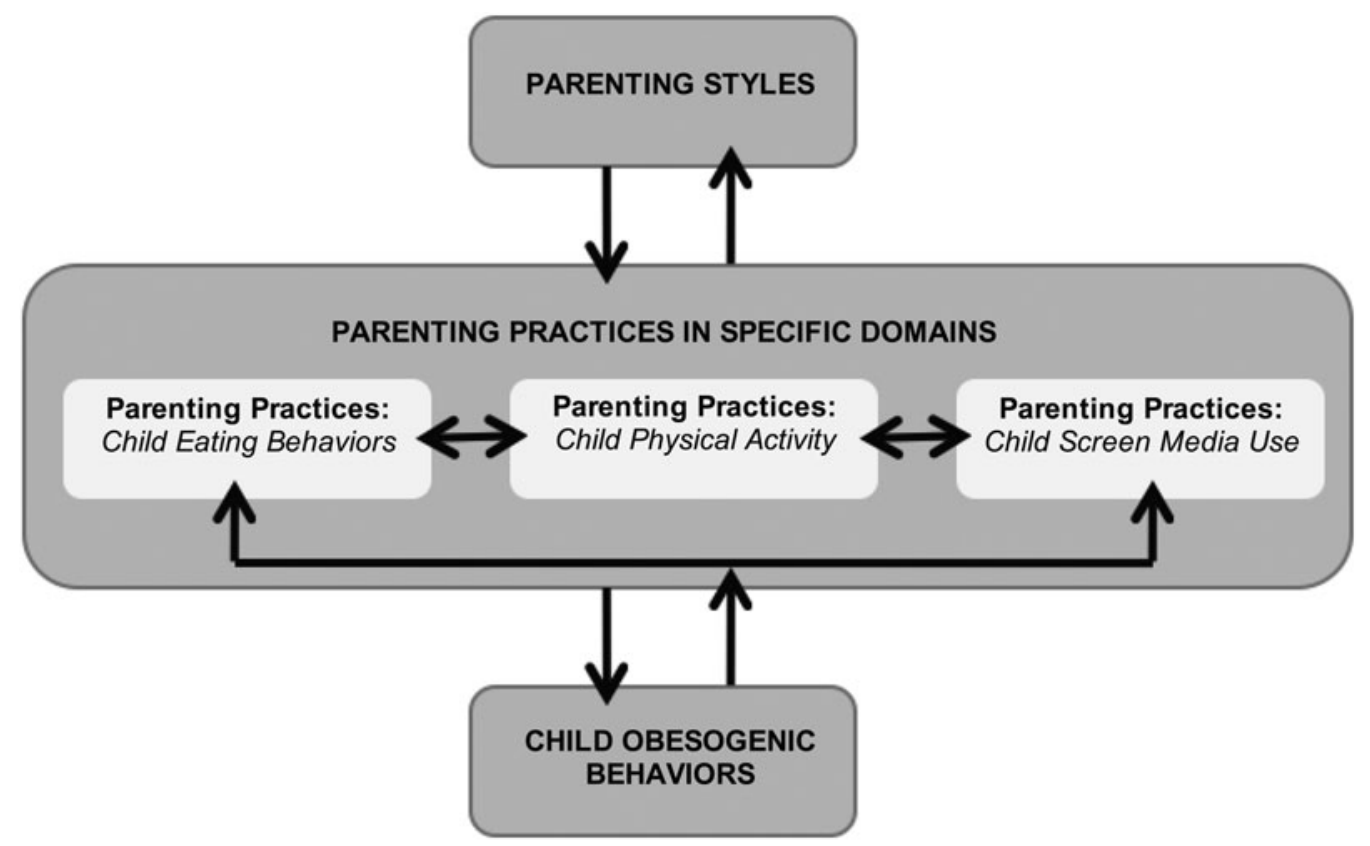

Figure 1. A hierarchical model of parenting styles, parenting practices, and children's obesogenic behaviors.

be perceived in similar or dissimilar ways. There are two versions of the Perceptions of Parents scales: One that has been developed and validated for late elementary and middle school students ${ }^{57}$ and another that has been developed and validated for college students. (Robbins RJ. "An assessment of perceptions of parental autonomy support and control: Child and parent correlates." Unpublished Doctoral dissertation, Department of Psychology, University of Rochester, 1994.) The availability of measures across different age groups is important because it provides an opportunity to study how relationships between parents and children change over time and is sensitive to developmental differences that naturally emerge in parent-child interactions. For example, to assess the extent to which parents provide unconditional positive regard, the child version of the scale asks children to indicate whether their parents think it is OK for children to make mistakes. In the college student version of the scale, young adults are asked to indicate whether they feel that their parents like them for who they are. These items clearly assess the same construct but do so somewhat differently based on the developmental stage of the child, adolescent, or young adult. Given the lack of measures of parenting styles for obesogenic behaviors, the approaches taken by SDT researchers, and of course by those working in the broader child development literatures, could inform future measurement development.

A systems science approach for parenting and childhood obesity. Obesity has been described as a complex public health problem that is deeply embedded within political, societal, cultural, and individual experiences. ${ }^{26}$ For childhood obesity in particular, no doubt this acknowledgement of the complexity of the problem and recognition of parents as a child's first socializing agent has fueled much of the research described above and throughout this special issue. However, less attention has been given to the mechanisms of parental influence over children's obesogenic behaviors or how broader social and environmental contexts may shape parents' efforts at socializing their children around these behaviors. Furthermore, a major criticism of the social-ecological model and similar approaches is that they have been used in largely unidirectional ways, testing how factors at one level of the model (e.g., the built environment) influence behaviors at another level of the model (e.g., children's levels of physical activity), with little acknowledgement of how different levels interact with, reinforce, or work against each other.

Systems science may be used to provide an overview of how elements at different levels within the socialecological framework interact and demonstrate the dynamics of connections within and among entities of the broader system. ${ }^{58,59}$ Systems science is naturally suited for evaluating the multilevel, complex components involved not only in children's obesogenic behaviors but, as noted earlier, how these components influence parenting styles and practices and change over time. Systems science also offers a suite of methodologies for studying family systems theory applications in children's weight and obesogenic behaviors. It is worth noting that family systems theory and systems science methodologies are not interchangeable terms or concepts. Family systems theory represents a particular theoretical perspective regarding the relationships among members within the family system. Systems science methods offer a broad suite of methodological tools to study not only the emotional climate and 
interrelations among family members but also the broader social, cultural, and environmental milieu from which parenting styles and practices and children's obesogenic behaviors emerge.

Different methodologies from systems science may serve to address and inform the scientific gaps noted in this article. For example, system dynamics models are designed to help identify the structure or set of relationships that drive behavior and provide insight into what changes may lead to positive behavior change. A system dynamics approach is both qualitative and quantitative. It begins with the development of a qualitative, causal loop diagram to model the system under study and then uses this diagram to develop mathematical models and computer simulations. Computer simulations allow users to identify and test "what if" scenarios beyond what is provided by existing data. ${ }^{60}$ In the context of parenting and children's obesogenic behaviors, the system of interest may operate at the dyadic (i.e., parent-child or co-parent), family, or neighborhood levels. The behavior of the system under study may be a child's ability to self-regulate and how this ability changes over time in response to different individual, parent, home, or neighborhood characteristics.

Figure 2 illustrates a simple causal loop diagram (i.e., qualitative systems model) of the parent-child relationship in the context of restrictive feeding. It is meant to be illustrative, not exhaustive, and is based in part on the existing evidence. An essential feature of system dynamics modeling is feedback, or closed chain, causal loops that drive system behavior. ${ }^{60}$ Figure 2 illustrates this system property through the reinforcing feedback loop (R1). In this example, the reinforcing loop (R1) reflects a cycle of dysregulation. The loop can be read as follows: As parental feeding restriction increases, the child's capacity to selfregulate decreases $(\mathrm{O}){ }^{61-63}$ As the child's capacity to selfregulate decreases, child energy intake increases $(\mathrm{O}){ }^{64}$ Along this pathway, as child energy intake increases, child BMI increases (S). ${ }^{65}$ As child BMI increases, parental feeding restriction increases (S). ${ }^{66}$ Reinforcing feedback loops are important because they reflect the ways in which cycles within the system continue and potentially escalate.

In the example presented in Figure 2, the reinforcing loop that characterizes how parental feeding restriction, child self-regulatory capacity, and child energy intake interrelate would have to be broken to effectively stop increasing child BMI. In this model, "O" represents a change in the opposite direction (e.g., child self-regulation decreases, energy intake increases) and " $S$ " represents a change in the same direction (e.g., child energy intake increases, child BMI increases). The model also shows that other auxiliary variables may feed into this loop. As an authoritarian parenting style increases, child willingness to be socialized decreases $(\mathrm{O})$, which may in turn lead to an increase in parental restriction $(\mathrm{O}){ }^{22}$ As an authoritarian parenting style increases, feeding restriction parenting practices may also increase (S). ${ }^{24}$ Reimagining our current unidirectional, linear models from a systems perspective can help to expand the science on the role of parenting in children's obesogenic behaviors and better capture the complex, interrelated factors that contribute both to parenting styles and practices and to children's obesogenic behaviors. These methodologies may guide the development of measurement tools that capture and evaluate

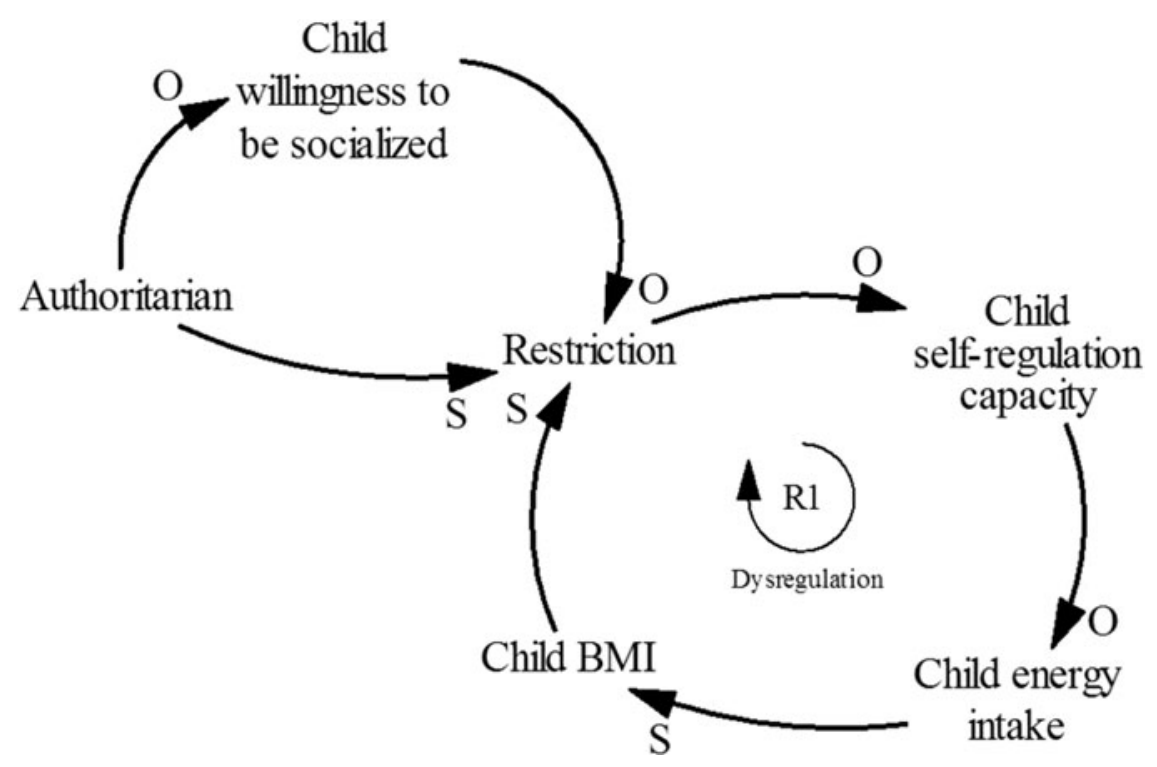

Figure 2. Causal loop diagram of the parent-child restrictive feeding relationship. Note that this is a simplified model for illustrative purposes only; other important feedback loops and variables may, of course, exist. $\mathrm{S}$, the second variable changes in the same direction as the first (can also be noted as a " $+"$ sign), all else equal; $\mathbf{O}$, the second variable changes in the opposite direction as the first (can also be noted as a " $"$ " sign), all else equal; R1, reinforcing loop 1. 
feedback across multiple levels of the system and, importantly, between parents and children. System dynamics models may also be used in intervention design, including the use of simulation models to test "what if" scenarios that may unfold as a result of targeting intervention efforts toward different parts of the system.

Agent-based modeling is another modeling approach that may offer unique insights for understanding parentchild relationships in the context of obesity and obesogenic behaviors. In comparison to system dynamics modeling, agent-based modeling is a computational method that enables a researcher to create, analyze, and experiment with models composed of agents that interact within an environment. ${ }^{67}$ This is in contrast to a system dynamics approach that focuses on an aggregate- rather than individual-level agents. Within the context of parent-child relationships, a parent or child could be assigned as an agent to evaluate how they interact with other agents and their environment. Agents can have heterogeneous attributes, such as parenting style typology with particular parenting practices embedded in their characteristics. One could then model how these agents interact with aspects of their environment such as specific child characteristics like age, gender, weight status, temperament; their broader social network or physical environment; or a combination of features. Regardless of the approach used, systems methods offer a unique way to study mechanisms of parental influence and may inform intervention design and assessment of novel constructs in addition to addressing the scientific gaps noted above.

\section{Discussion}

As a primary socializing agent, parents play an important role in the development and maintenance of children's obesogenic behaviors. ${ }^{17}$ To date, the literature on parenting styles and practices, as applied to these behavioral domains, has provided important insights into the ways in which particular parenting practices may facilitate or undermine behaviors, such as eating fruit and vegetables, limiting junk food intake, engaging in regular physical activity (or play), and limiting screen media use. Nonetheless, there are important gaps in the existing literature that must be filled to develop a comprehensive science of parenting in childrens' obesogenic behaviors and develop interventions that will effectively change relevant behaviors in children and parents to curb the obesity epidemic.

Much of the existing literature on parenting and obesogenic behaviors has focused almost exclusively on parenting practices, with little consideration of parenting styles. As has been demonstrated in the more general literature on child development, parenting styles reflect the broader emotional climate that parents create in their interactions with children and thus may play an important moderating role in the link between parenting practices and obesogenic behaviors. Additionally, very little research has addressed the mechanisms through which parenting practices influence obesogenic behaviors. Identifying mechanisms (i.e., mediators, moderators) is important for addressing more proximal targets of change and may serve to inform the development of interventions. Parenting styles and practices emerge from a broader social and contextual milieu, and research is needed on the precursors to parenting styles and practices in the context of childhood obesity. Characterizing how various factors in neighborhoods, cultures, and interpersonal relationships influence how parents interact with their children will further our understanding of the contexts in which parenting practices occur. It will also further clarify the complex interrelationships between broader social and cultural variables, parents, children, and other relationships. Finally, the literature on the role of parenting in children's obesogenic behaviors needs to shift from being unidirectional to multidirectional and begin to capitalize on data from multiple members within the same family, including parents, children, and even siblings.

A conceptual framework is needed to guide future research and address the scientific gaps raised here, as well as others. Because of its conceptual similarity to the literature on parenting styles and its identification of self-regulation as an important variable in the pathway between the social context (e.g., psychological need support, parenting styles, or practices) and children's behavioral outcomes, self-determination theory may be one candidate perspective to consider. Systems science also has much to offer by way of providing a suite of methods for addressing the complex ways in which parents, children, the cultural context, the food and built physical environment, and other factors influence parenting styles and practices and, ultimately, children's obesogenic behaviors. The use of novel approaches, such as system dynamics or agent-based modeling, may yield important insight into the ways in which various facets interact, have mutual, reciprocal influence on each other, and provide a means by which to better understand and measure dynamic relationships between individuals, relationships, and social and cultural contexts.

Measurement issues transcend all of these scientific gaps. There is a need for improved measures of parenting style that more closely reflect the emotional and relational climate created by parent-child interactions and are not simply aggregates of specific parenting practices. Conceptualizing parenting styles as experiential rather than as a behavioral manifestation may be one approach. It is also critical to incorporate better measurement of potential mediators and moderators of the associations between parenting practices and children's obesogenic behaviors. Several mediators and moderators, including children's self-regulation, have been hypothesized, but few have been directly tested in obesity and related behavioral domains. Research that incorporates measures of broader relational dynamics, perceptions of cultural norms, objective and subjective measures of the food and physical activity environments, and other factors that may influence how parents interact with children is greatly needed. Finally, the 
literature on parenting and childhood obesity cannot be complete without consideration of the relationships and relational dynamics involved. This will require assessing parenting styles and practices from the perspective of all parties involved-parents, co-parents, and children. Therefore, measures should be developed that compare constructs measured across the developmental trajectory. In particular, parents' report of their own behavior should measure the same constructs as child reports relating to perceptions of their parents' behaviors. Having relevant measures across the life span will enable measurement in longitudinal studies to address the changing dynamics of parent-child interactions around obesogenic behaviors across developmental periods.

\section{Conclusion}

Given the childhood obesity epidemic and increasing emphasis on targeting multilevel influences on obesogenic behaviors, the window for pushing the science forward in parenting styles and practices is primed. Capitalizing on current evidence from the broader developmental and psychological literatures and leveraging new multidisciplinary approaches offer exciting potential for more outcomes-oriented interventions and long-term health behavior change in children and adults. Because of the potential for parents to influence child behavior throughout early development into adulthood, the science of parenting in children's obesogenic behaviors has tremendous potential for future public health impact.

\section{Acknowledgments}

This project has been funded in whole or in part with federal funds from the National Cancer Institute (NCI), National Institutes of Health, under contract no. HHSN261200800001E. The content of this publication does not necessarily reflect the views or policies of the Department of Health and Human Services, nor does mention of trade names, commercial products, or organizations imply endorsement by the US Government. Erin Hennessy is supported through a Cancer Research Training Award from the Cancer Prevention Fellowship Program.

The authors wish to thank Linda Nebeling, Chief, Health Behaviors Research Branch, Behavioral Research Program, Division of Cancer Control and Population Sciences at the National Cancer Institute for her scientific and administrative support of the NCI-sponsored meeting on the role of parents in children's cancer-preventive behaviors. We further wish to thank Michele Fisher, Ashley Holmes, and Rebecca Roth for their assistance with meeting logistic support. We would also like to thank the scientific experts who participated in the NCI-sponsored meeting: Guadalupe Ayala, Nancy Darling, Kirsten Davison, Jay Fagan, Jennifer Fisher, Wendy Grolnick, Melanie Hingle, Eric Hodges, Sheryl Hughes, Jon Macy, Teresia O'Connor, Tom Power, and Dianne Ward. We also thank Sheryl
Hughes and Teresia O'Connor for comments on an earlier draft of this manuscript.

We also thank Tom Baranowski, Professor of Pediatrics at Baylor College of Medicine, Children's Nutrition Research Center, and the planning committee for the invitation to participate in the ISBNPA Pre-Conference Workshop. The preconference to the 2012 International Society for Behavioral Nutrition and Physical Activity (ISBNPA) annual meeting, "Parenting Measurement: Current Status and Consensus Reports" and resulting manuscripts were made possible due to funding from the United States Department of Agriculture/Agricultural Research Service (USDA/ARS 2012-68001-19285) and the National Heart, Lung, and Blood Institute of the National Institutes of Health (R13HL114262).

\section{Author Disclosure Statement}

The authors declare that they have no competing financial interests.

\section{References}

1. Ogden CL, Carroll MD, Kit BK, et al. Prevalence of obesity in the United States. NCHS Data Brief 2012;82:1-8.

2. Craigie AM, Lake AA, Kelly SA, et al. Tracking of obesity-related behaviours from childhood to adulthood: A systematic review. Maturitas 2011;70:266-284.

3. American Institute for Cancer Research. Food, Nutrition, Physical Activity, and the Prevention of Cancer: A Global Perspective. World Cancer Research Fund: Washington, DC, 2007.

4. Gordon-Larsen P, Adair LS, Nelson MC, et al. Five-year obesity incidence in the transition period between adolescence and adulthood: The National Longitudinal Study of Adolescent Health. Am J Clin Nutr 2004;80:569-575.

5. Power TG. Parenting dimensions and styles: A brief history and recommendations for future research. Child Obes 2013;9(S1): S-14-S-21.

6. Baumrind D. Current patterns of parental authority. Devel Psychol Monographs 1971;4(Part 2):1-103.

7. Maccoby EE, Martin JA. Socialization in the context of the family: Parent-child interaction. In: Mussen PH, Hetherington EH (eds), Handbook of Child Psychology: Vol 4. Socialization, Personality and Development, $4^{\text {th }}$ ed. Wiley: New York, 1983.

8. Steinberg L. Adolescent transitions and other drug use prevention. In Goplerud E (ed), Preventing Adolescent Drug Use: From Theory to Practice. Office of Substance Abuse Prevention, US Department of Health and Human Services (OSAP Prevention Monograph-8): Washington, 1992, pp. 13-51.

9. Weber Cullen K, Baranowski T, Rittenberry L, et al. Social-environmental influences on children's fruit, juice, and vegetable consumption as reported by parents: Reliability and validity of measures. Public Health Nutr 2000;3:345-356.

10. Gable S, Lutz S. Household, parent, and child contributions to childhood obesity. Fam Rel 2000;49:293-300.

11. Chaudhuri JH, Easterbrooks MA, Davis CR. The relation between emotional availability and parenting style: Cultural and economic factors in a diverse sample of young mothers. Parenting: Science and Practice 2009;9:277-299. 
12. Chao RK. Beyond parental control and authoritarian parenting style: Understanding Chinese parenting through the cultural notion of training. Child Devel 1994;65:1111-1119.

13. Chao RK. The parenting of immigrant Chinese and European American mothers: Relations between parenting styles, socialization goals, and parenting practices. J Appl Devel Psychol 2001; 21:233-248.

14. Chen J, Kennedy C. Family functioning, parenting style and Chinese children's weight status. J Fam Nurs 2004;10:262-279.

15. Chen J, Kennedy C. Cultural variation in children's coping, media use and family functioning. Int Nurs Rev 2005;52:1-25.

16. Hurley KM, Cross MB, Hughes SO. A systematic review of responsive feeding and child obesity in high-income countries. $J$ Nutr 2011;141:495-501.

17. Berge JM. A review of familial correlates of child and adolescent obesity: What has the $21^{\text {st }}$ Century taught us so far? J Adolesc Med Health 2009;21:457-483.

18. Hennessy E, Hughes SO, Goldberg JP, et al. Parent-child interactions and objectively measured child physical activity: A crosssectional study. Int J Behav Nutr Phys Act 2010;7:71.

19. Jago R, Davison KK, Brockman R, et al. Parenting styles, parenting practices, and physical activity in 10- to 11-year olds. Prev Med 2011;52:44-47.

20. Jago RP, Davison KK, Thompson JL, et al. Parental sedentary restriction, maternal parenting style, and television viewing among 10- to 11-year olds. Pediatrics 2011;128:e572-e578.

21. Darling N, Steinberg L. Parenting style as context: An integrative model. In: Laursen B, Zukauskiene R (eds), International Library of Psychology: Interpersonal Development. Ashgate Publishers: Hampshire, UK, 2007.

22. Kitzmann KM, Beech BM. Family-based interventions for pediatric obesity: Methodological and conceptual challenges from family psychology. J Fam Psychol 2006;20:175-189.

23. Ventura AK, Birch LL. Does parenting affect children's eating and weight status? Int J Behav Nutr Phy Act 2008;5:15.

24. Frankel LA, Hughes SO, O'Connor TM, et al. Parental influences on children's self-regulation of energy intake: Insights from developmental literature on emotion regulation. J Obes 2012;327259.

25. Huang TT, Glass TA. Transforming research strategies for understanding and preventing obesity. JAMA 2008;300:1811-1813.

26. Hammond RA. Complex systems modeling for obesity research. Prev Chronic Dis 2009;6:A97.

27. Campbell J, Gilmore L. Intergenerational continuities and discontinuities in parenting styles. Australian J Psychol 2007;59: $140-150$.

28. Macintyre S, Ellaway A. Ecological approaches: Rediscovering the role of the physical and social environment. In: Berkman LF, Kawachi I (eds), Social Epidemiology. Oxford Unviersity Press, Inc.: New York, 2000, pp. 332-348.

29. Kumanyika SK, Obarzanek E, Stettler N, et al. Population-based prevention of obesity: The need for comprehensive promotion of healthful eating, physical activity, and energy balance: A scientific statement from American Heart Association Council on Epidemiology and Prevention, Interdisciplinary Committee for Prevention (formerly the expert panel on population and prevention science). Circulation 2008;118:428-464.

30. Glanz K, Bader MD, Iyer S. Retail grocery store marketing strategies and obesity: An integrative review. Am J Prev Med 2012; 42:503-512.

31. Marshall SJ, Gorely T, Biddle SJ. A descriptive epidemiology of screen-based media use in youth: A review and critique. J Adolesc 2006;29:333-349.
32. Bluestone C, Tamis-LeMonda CS. Correlates of parenting style in predominantly working- and middle-class African American mothers. J Marriage Fam 1999;61:881-893.

33. Belsky J, Herzog C, Rovine M. Causal analysis of multiple determinants of parenting: Empirical and methodological advances. In: Lamb L, Brown A, Rogoff B (eds), Advances in Developmental Psychology. Erlbaum: Hillsdale, NJ, 1986, pp. 193-217.

34. McPhie S, Skouteris H, Daniels L, et al. Maternal correlates of maternal child feeding practices: A systematic review. Matern Child Nutr 2012, doi: 10.1111/j.1740-8709.2012.00452.x. [Epub ahead of print]

35. deHaan AD, Prinzie P, Dekovic M. Change and reciprocity in adolescent aggressive and rule-breaking behaviour and parental support and dysfunctional discipline. Dev Psychopathol 2012;24: $301-315$

36. Williams SR, Kertz SJ, Schrock MD, et al. A sequential analysis of parent-child interactions in anxious and nonanxious families. $J$ Clin Child Adolesc Psychol 2012;41:64-74.

37. Berge JM, Wall M, Loth K, et al. Parenting style as a predictor of adolescent weight and weight-related behaviors. J Adolesc Health 2010;46:331-338.

38. Wake M, Nicholson JM, Hardy P, et al. Preschooler obesity and parenting styles of mothers and fathers: Australian national population study. Pediatrics 2007;120:e1520-e1527.

39. Grall TS. Custodial Mothers and Fathers and Their Child Support. Current Population Reports, P60-237, US Census Bureau, Washington, DC, 2009.

40. Fagan J, Palkovitz R, Roy K, et al. Pathways to paternal engagement: Longitudinal effects of cumulative risk and resilience on nonresident fathers. Devel Psychol 2009;45:1389-1405.

41. Laughlin L, Farrie D, Fagan J. Father involvement with children following marital and non-marital separations. Fathering 2009;7: $226-248$

42. Comella PA. Observations of reciprocal functioning in a challenging environment. Family Systems 2003;6:101-116.

43. Deci EL, Ryan RM. The 'what' and 'why' of goal pursuits: Human needs and the self-determination of behavior. Psychol Inquiry 2000;11:227-268.

44. Ryan RM, Deci EL. Self-determination theory and the facilitation of intrinsic motivation, social development, and well-being. $\mathrm{Am}$ Psychol 2000;55:68-78.

45. Ryan RM. Psychological needs and the facilitation of integrative processes. J Pers 1995;63:397-427.

46. Grolnick WS. The Psychology of Parental Control: How WellMeant Parenting Backfires. Erlbaum: Mahwah, NJ, 2003.

47. Grolnick WS. The role of parents in facilitating autonomous selfregulation for education. Theory Res Educ 2009;7:164-173.

48. Roth G, Assor A, Niemiec CP, et al. The emotional and academic consequences of parental conditional regard: Comparing conditional positive regard, conditional negative regard, and autonomy support as parenting practices. Devel Psychol 2009;45: 1119-1142.

49. Assor A, Vansteenkiste M, Kaplan A. Identified versus introjected approach and introjected avoidance motivations in school and in sports: The limited benefits of self-worth strivings. J Educ Psychol 2009; 101:482-497.

50. Roth G, Assor A. Parental conditional regard as a predictor of deficiencies in young children's capacities to respond to sad feelings. Inf Child Devel 2010;19:465-477.

51. Soenens B, Vansteenkiste M. A theoretical upgrade of the concept of parental psychological control: Proposing new insights on the basis of self-determination theory. Devel Rev 2010;30:74-99. 
52. Ryan RM, Deci EL, Grolnick WS, et al. The significance of autonomy and autonomy support in psychological development and psychopathology. In: Cicchetti D, Cohen DJ (eds), Developmental Psychopathology: Theory and Method, 2nd ed., vol. 1. John Wiley \& Sons, Inc.: New Jersey, 2006, pp. 795-849.

53. Teixeira PJ, Silva MN, Mata J, et al. Motivation, selfdetermination, and long-term weight control. Int $J$ Behav Nutr Phys Act 2012;9:22.

54. Vallerand RJ. Toward a hierarchical model of intrinsic and extrinsic motivation. In: Zanna MP (ed), Advances in Experimental Social Psychology, vol. 29. Academic Press: San Diego, 1997, pp. 271-360.

55. Patrick H, Williams GC. Self-determination theory: Its application to health behavior and complementarity with motivational interviewing. Int J Behav Nutr Phys Act 2012;9:18.

56. Teixeira PJ, Carraça EV, Markland DA, et al. Exercise, physical activity, and self-determination theory: A systematic review [Electronic version]. Int J Behav Nutr Phys Act 2012;9:78.

57. Grolnick WS, Ryan RM, Deci EL. The inner resources for school performance: Motivational mediators of children's perceptions of their parents. J Educ Psychol 1991;83:508-517.

58. Best A. Systems thinking and health promotion. Am J Health Prom 2011;25:4.

59. Holmes BJ, Finegood DT, Riley BL, et al. Systems thinking in dissemination and implementation research. In Brownson RC, Colditz GA, Proctor EK (eds), Dissemination and Implementation Research in Health: Translating Science to Practice. Oxford University Press: New York, 2012.

60. Sterman JD. Business Dynamics: Systems Thinking and Modeling for a Complex World. Irwin/McGraw-Hill: New York, 2000.

61. Fisher JO, Birch LL. Restricting access to foods and children's eating. Appetite 1999;32:405-419.
62. Birch LL, Fisher JO, Davison KK. Learning to overeat: Maternal use of restrictive feeding practices promotes girls' eating in the absence of hunger. Am J Clin Nutr 2003;78:215-220.

63. Fisher JO, Birch LL. Eating in the absence of hunger and overweight in girls from 5 to $7 \mathrm{y}$ of age. Am J Clin Nutr 2002;76: 226-231.

64. Fisher JO, Birch LL. Restricting access to palatable foods affects children's behavioral response, food selection, and intake. Am J Clin Nutr 1999;69:1264-1272.

65. Francis LA, Susman EJ. Self-regulation and rapid weight gain in children from age 3 to 12 years. Arch Pediatr Adolesc Med 2009; 163:297-302.

66. Faith MS, Scanlon KS, Birch LL, et al. Parent-child feeding strategies and their relationships to child eating and weight status. Obes Res 2004;12:1711-1722.

67. Gilbert N. Agent-Based Models (Quantitative Applications in the Social Sciences). Sage Publications, Inc.: Thousand Oaks, CA, 2008.

Address correspondence to: Heather Patrick, PhD

Health Scientist/Program Director National Cancer Institute

Division of Cancer Control and Population Sciences Behavioral Research Program, Health Behaviors Research Branch 9609 Medical Center Drive, Room 3E112 MSC 9671 Bethesda, MD 20892-9671

E-mail: patrickha@mail.nih.gov 